\title{
Effects of speech motor practice and linguistic complexity on articulation rate in adults who stutter*
}

\author{
HeeCheong Chon ${ }^{1, * *} \cdot$ Torrey M. Loucks ${ }^{2,3}$ \\ ${ }^{I}$ Department of Speech-Language Pathology, Chosun University, Gwangju, Korea \\ ${ }^{2}$ Department of Communication Sciences and Disorders, University of Alberta, Edmonton, AB, Canada \\ ${ }^{3}$ Institute for Stuttering Treatment and Research ISTAR, University of Alberta, Edmonton, AB, Canada
}

\begin{abstract}
This study aimed to investigate speech motor control in adults who stutter (AWS) by testing whether articulation rate changes with practice and linguistic complexity. Eleven AWS and 11 adults who do not stutter (AWNS) repeated four sentences of different lengths and syntactic complexity [simple-short (SS), simple-long (SL), complex-long (CL), and faulty-long (FL) sentences]. Overall articulation rates of each sentence were measured and compared between groups. Practice effects were evaluated by comparing the articulation rates of the first three, middle four, and last three productions. Overall, the AWS had significantly slower articulation rates than AWNS across the four sentences. The longer sentences showed significantly slower articulation rates than the baseline sentence (SS). The articulation rates of the middle four and the last three productions were significantly faster than those of the first three productions of each sentence in both groups. The articulation rates of the SS, SL, and CL sentences indicated a consistent practice effect. The slower articulation rates of the AWS are consistent with a speech motor limitation. There was no interaction with linguistic complexity or practice, so a slower articulation rate may be a general feature of the speech of AWS. Both AWS and AWNS showed practice effects with faster articulation rates which may reflect a degree of adaptation to the stimuli.
\end{abstract}

Keywords: adults who stutter, articulation rate, practice effect, speech motor control

\section{1. 서론}

발달성말더듬(developmental stuttering, 이하 말더듬)은 아직
정확한 원인이 밝혀지지 않은 말장애이다. 말더듬는 사람은 말 산출 시 비정상적 비유창성이 발생하는 말 붕괴(disruption)를 보이며, 이로 인하여 말의 정상적인 흐름에 방해가 발생한다

\footnotetext{
* The data were collected for the first author's doctoral dissertation, which was conducted through the Illinois International Stuttering Research Program and the NeuroSpeech Lab at the University of Illinois at Urbana-Champaign. This work was supported by grant \# R01-DC05210 from the National Institutes of Health, National Institute on Deafness and Other Communication Disorders (Ehud Yairi, original PI; Nicoline G. Ambrose, second PI; Torrey M. Loucks, Co-PI). It was also supported by a University of Illinois Research Board grant (Torrey M. Loucks, PI).

** hchon@chosun.ac.kr, Corresponding author

Received 14 August 2021; Revised 7 September 2021; Accepted 7 September 2021

(c) Copyright 2021 Korean Society of Speech Sciences. This is an Open-Access article distributed under the terms of the Creative Commons Attribution NonCommercial License (http://creativecommons.org/licenses/by-nc/4.0) which permits unrestricted non-commercial use, distribution, and reproduction in any medium, provided the original work is properly cited.
} 
(Wingate, 1964). 말더듬을 다요인적인 관점으로 설명하는 역동 적-다중요인모델은 말 산출을 위한 운동 시스템이 다양한 요인 들, 즉, 언어적, 정서적, 인지적 요인 등과 상호작용하여 이러한 말 붕괴가 발생한다고 주장하였다(Smith \& Kelly, 1997; Smith \& Weber, 2017). 또한 말더듬는 사람의 말 산출을 위한 운동 시스 템은 유창하게 말을 산출할 때에도 불안정성(instability)과 비일 관성(inconsistency)을 보이며 다양한 요인의 영향으로 인해 불 안정성과 비일관성이 증가할 수 있다고 하였다(Bauerly et al., 2019; Smith \& Weber, 2017; Smith et al., 2010). 선행연구들은 말 더듬는 사람의 말운동 특성을 파악하기 위하여 행동적인 방법 (Sasisekaran, 2012; Sasisekaran \& Weisberg, 2014), 운동적인 방 법(Kleinow \& Smith, 2000), 혹은 음향적인 방법(Chon \& Lee, 2019; Hall et al., 1999)을 사용하였다. 연구마다 다소 차이는 있 지만 행동적인 방법을 사용한 연구들은 말더듬는 사람이 말 산 출과제 수행 시 수행 정확도가 낮거나 오류의 빈도가 상대적으 로 높은 모습을 보인다(Sasisekaran \& Weisberg, 2014)고 하였다. 운동적인 방법을 사용한 연구들은 유창한 발화만을 사용하여 집단 간 비교를 실시하였으며, 전반적으로 말더듬는 사람의 말 운동안정성(speech motor stability)이 말을 더듬지 않는 사람보 다 낮았고 구문적 복잡성이 높아질수록 말운동안정성은 더 낮 게 나타났다고 보고하였다(Kleinow \& Smith, 2000; Usler et al., 2017 등).

조음속도는 말운동 특성을 파악하기 위해 조음기관 움직임 의 속도를 측정하는 음향적인 분석방법이다(Chon \& Lee, 2016). 조음속도는 말 산출 시 조음기관 움직임의 조직성과 협응 능력 을 간접적으로 살펴 화자의 말운동통제 능력을 파악할 수 있는 장점이 있다(Chon et al., 2012; Zebrowski, 1995). 조음속도는 다 양한 요인의 영향을 받는다. 화자 내 요인(내재적 요인)으로는 화자가 산출하려는 발화의 길이와 복잡성, 담화의 복잡성, 말운 동 능력, 불안과 같은 말-언어적 측면과 정서적인 측면이 포함 되고(Goberman et al., 2011; Howell et al., 1999; Jacewicz et al., 2009; Quené, 2008; Usler \& Walsh, 2018), 화자 간 요인(외재적 요인)에는 출신 혹은 거주지역, 학력, 사회경제적 지위, 성별, 연 령, 말 산출 과제 등이 있다(Ahn et al., 2002; Amir \& Grinfeld, 2011; Jacewicz et al., 2009; Jacewicz et al., 2010; Logan et al., 2011).

말더듬 분야에서는 심리언어학적인 관점에서 말더듬과 말속 도의 관련성이 논의되었으며(Postma \& Kolk, 1993), 조음속도가 말더듬는 사람의 말운동통제 능력을 나타내는 지표 중 하나로 여겨지고 있다(Hall et al., 1999). 또한 느린 조음속도는 비유창 성의 가능성을 낮출 수 있으며(Kloth et al., 1995) 말더듬 치료접 근법인 유창성완성법은 유창한 말을 산출하기 위하여 조음기 관 움직임의 속도를 줄이는 방법, 즉, 조음속도를 감소시키는 방법을 사용하고 있다(Manning, 2010). 말더듬는 사람의 조음속 도 특성을 말을 더듬지 않는 사람과 비교한 연구들은 주로 학령 전 아동을 대상으로 이루어졌다(Chon \& Lee, 2016; Hall et al., 1999; Kloth et al., 1995; Meyers \& Freeman, 1985 등). 이는 말더 듬이 시작된지 얼마되지 않은 어린 아동을 대상으로 하여 말더
듬의 시작과 관련된 특성을 밝히고자 하였기 때문이다. 학령전 아동을 대상으로 이루어진 연구들은 말더듬 아동이 일반 아동 보다 조음속도가 느리거나(Hall et al., 1999; Meyers \& Freeman, 1985) 두 집단 간 차이가 없거나(Chon \& Lee, 2016) 오히려 말더 듬 아동의 조음속도가 빨랐다(Kloth et al., 1995)는 비일관된 결 과를 보고하였다. 이러한 비일관된 결과는 다양한 요인의 영향 을 받는 조음속도의 특성상 실험설계상의 차이로 인한 것일 수 있으며, 어린 말더듬 아동은 말운동 기술이 발달하고 있는 시기 이기 때문에 연구에 참여한 아동 개인에 따른 영향일 수도 있을 것이다. 따라서 어린 아동을 대상으로 이루어진 집단 간 비교 연구 결과를 말더듬 성인(adults who stutter, AWS)에게 직접적 으로 적용하는 것에는 한계가 있다.

말더듬 아동과 달리 AWS의 조음속도 특성을 살핀 연구는 제 한적으로 이루어졌으며, 대부분의 연구는 집단 간 비교가 아니 라 AWS 집단 내에서 중증도나 과제, 조음속도 측정방식에 따 른 특성을 보는 연구들이었다(Chon \& Lee, 2019; de Andrade et al., 2003; Park \& Kwon, 2010; Park et al., 2015). 연구 결과들은 AWS는 말더듬 중증도가 심할수록 조음속도가 느렸으며(de Andrade et al., 2003; Park \& Kwon, 2010), 발화 내 비유창성 출현 유무에 따른 조음속도에 유의한 차이를 보이지 않았고(Chon \& Lee, 2019), 배경소음 유형에 따른 조음속도에도 유의한 차이가 없었다(Park et al., 2015)고 하였다. AWS와 말을 더듬지 않는 성 인(adults who do not stutter, AWNS)의 조음속도를 실험 상황에 서 직접적으로 비교한 연구는 최근에 이루어졌다(Bauerly et al., 2019). Bauerly et al.(2019)이 AWS와 AWNS가 사회적 스트레스 상황에서 조음속도에 차이가 있는지를 비교한 결과, AWS는 AWNS보다 빠른 조음속도를 보이는 것으로 나타났다. 연구자 들은 이러한 결과가 사회적 스트레스 상황에 대한 AWS의 불안 수준이 높았기 때문인 것으로 해석하였다.

최근 연구들은 단어나 비단어 과제를 사용하여 말더듬는 사 람의 말 산출 특성뿐 아니라 운동기술 학습 능력을 살피고 있다 (Bauerly \& De Nil, 2011; Sasisekaran \& Weisberg, 2014; Smith et al., 2010; Smits-Bandstra et al., 2006). 운동기술 학습 능력은 동 일한 말 산출 과제를 반복하여 수행하였을 때 운동 연습효과 (practice effect)가 나타나는가를 확인하는 방식으로 이루어졌으 며, 여기에서 ‘연습’이란 “한 실험 세션 내에서 수행력이 증진되 는 것(Sasisekaran \& Weisberg, 2014:56)”이라고 정의하였다. 운 동적인 방법을 사용한 Smits-Bandstra et al.(2006)은 AWS와 AWNS간 비단어 산출 시 연습효과에 차이가 없음을 보고하였 는데, 연구자들은 그 이유를 과제의 난이도가 낮아 집단 간 차 이를 찾기 어려웠던 것으로 해석하였다. 이후에 이루어진 연구 들은 일관되게 AWS가 AWNS와 비교 시 전반적으로 말운동안 정성이 낮았고, 과제의 길이와 복잡성이 증가할수록 $\mathrm{AWS}$ 의 말 운동안정성이 더욱 낮아지는 모습이 나타났으며, 반복해서 산 출한 말 자료를 반으로 나누어 선행 말 자료와 후행 말 자료의 말운동안정성을 비교한 결과 AWS는 연습효과가 더디게 나타 났다고 보고하였다(Sasisekaran \& Weisberg, 2014; Smith et al., 2010). 예를 들어, Smith et al.(2010)은 AWS와 AWNS를 대상으 
로 길이와 복잡성을 다르게 한 4개의 비단어(1-4음절)를 산출하 게 하여 말운동안정성을 비교하였다. 그 결과 AWS가 AWNS보 다 전반적인 말운동안정성이 낮았으며, 각 비단어 별로 10 번씩 산출했던 말 자료를 선행하는 5 개와 후행하는 5 개로 나누어 집 단과 비단어 산출 순서 간 말운동안정성을 비교한 결과, AWNS 는 말운동안정성의 변화가 나타나지 않았던 반면 AWS는 선행 비단어보다 후행 비단어의 말운동안정성이 높게 나타났다. 즉, AWNS는 비단어 산출 시 초반에 이미 비단어 과제 산출을 위한 운동기술이 학습되어 말운동안정성 지표의 상한(ceiling) 값을 보인 반면 AWS는 반복되는 산출을 통하여 점차적으로 연습효 과가 발생한 것으로 해석할 수 있었다.

선행연구 결과는 $\mathrm{AWS}$ 가 $\mathrm{AWNS}$ 에 비해 전반적으로 말운동 안정성이 낮고, 연습효과가 더디게 나타나 AWS의 운동기술 학 습 능력이 늦거나 제한적임을 시사한다. 또한 말 과제의 길이와 복잡성이 운동기술 학습 능력에 영향을 미칠 수 있는 요인임을 알 수 있다. 하지만 말 산출 시 기저의 말운동안정성이 실제 조 음기관의 움직임에 영향을 주는지는 명확하지 않으며, AWS의 경우 연습효과의 상한이 어느 정도의 반복산출 후에 나타나는 지, 상한까지 도달하는 특성이 AWNS와 비교하였을 때 어떠한 지 확인하지 못하였다. 또한 운동기술 학습과 관련해서는 주로 운동적인 방법을 사용해왔기 때문에 음향적인 방법, 즉, 조음속 도를 측정하는 방법을 통하여 운동기술 학습이 실제 조음기관 의 움직임의 속도에 영향을 주는지 연구할 필요가 있을 것이다. 따라서 본 연구는 음향적인 분석방법인 조음속도 측정을 통하 여 AWS의 말 산출 특성과 운동기술 학습 능력을 AWNS와 비교 하여 파악하고자 하였다. 이때 말 과제의 길이와 복잡성이 조음 속도와 운동기술 학습에 영향을 미칠 수 있는 요인임을 감안하 여 문장의 길이와 복잡성을 달리한 말 산출 과제를 사용하였다. 구체적인 연구문제는 (1) AWS와 AWNS는 언어적 복잡성에 따 른 전체 조음속도에 차이가 있는가, (2) AWS와 AWNS는 언어 적 복잡성 및 문장산출 순서에 따른 조음속도에 차이가 있는가 였다.

\section{2. 연구방법}

\section{1. 연구 참여자}

본 연구의 참여자는 AWS 11명(남 7명, 여 4명)과 AWNS 11명 (남 7명, 여 4명)이었다. 모든 참여자는 만 19세 이상의 성인이었 으며, 고졸 이상의 학력으로 영어가 모국어인 단일언어 사용자 였다. AWS의 경우, (1) 100 음절당 3회 이상의 SLD를 산출하였 고, (2) 언어재활사에게 말더듬 장애로 진단받았으며, (3) 말더 듬 외에 말, 언어, 읽기, 청각, 시각 및 신경학적인 문제를 동반 하지 않는 참여자를 선정하였다. AWNS는 (1) 100음절당 3회 미 만의 SLD를 보였으며, (2) 언어재활사가 말더듬 문제가 없음을 확인하였고, (3) 말, 언어, 읽기, 청각, 시각 및 신경학적인 문제 를 동반하지 않는 참여자를 선정하였다.

AWS의 평균 연령은 23.27세(연령범위 19-34세)였으며, 일리 노이 말더듬중증도 척도(Illinois Clinician Stuttering Severity Scale,
Yairi \& Ambrose, 2005)를 사용한 말더듬 평가 결과, 6명은 약함, 5 명은 중간 정도의 중증도로 평가되었다. PPVT-III (Peabody Picture Vocabulary Test-III, Dunn \& Dunn, 1997)와 EVT(Expressive Vocabulary Test, Williams, 1997)를 사용한 언어검사 결과, 각각의 평균이 114.91 점 $(S D=9.30)$ 과 124.55점 $(S D=22.43)$ 으로 나타났다. AWNS 는 평균 연령이 21.72세(연령범위 21-23세)였으며, PPVT-III 평 균점수가 112.91 점 $(S D=8.36), \mathrm{EVT}$ 의 평균점수가 114.36 점 $(S D=$ $16.78)$ 이었다. 독립표본 $t$-검정을 실시한 결과, 두 집단의 연령과 언어점수에는 유의한 차이가 없는 것으로 나타났다(연령: $t=1.05$, $p=.317$; PPVT-III: $t=.053, p=.602$; EVT: $t=1.21, p=.242$ ). 모든 참 여자의 청력이 정상 범주인지 확인하기 위하여 $500 \mathrm{~Hz}, 1,000$ $\mathrm{Hz}, 2,000 \mathrm{~Hz}, 4,000 \mathrm{~Hz}$ 에서 $20 \mathrm{~dB} \mathrm{HL}$ 을 기준으로 청력 스크리 닝(GSI 17 audiometer, Grason-Stadler Inc)을 실시한 결과, 모든 연구 참여자의 청력이 정상 범주인 것으로 나타났다.

\section{2. 자료수집}

\subsection{1. 언어적 복잡성 과제}

언어적 복잡성에 따른 집단의 조음속도를 측정하기 위하여 길이와 복잡성이 다른 4 개의 문장을 구성하였다. 첫 번째 문장 은 기준(baseline) 문장으로 '짧고 단순한(simple-short, SS)' 문장 인 "Buy Bobby a puppy"이다. 이 문장은 다수의 선행연구에서 말더듬는 사람의 말운동안정성을 측정하기 위하여 사용해온 문장으로(Kleinow \& Smith, 2000; Maner et al., 2000; Sadagopan $\&$ Smith, 2008 등) 4 개의 단어와 6 개의 음절, 4 개의 형태소로 이 루어져 있다. 다른 3 개는 기준 문장보다 길고 복잡한 문장이며, 문법적인 경계 없이 한 호흡에 읽을 수 있는 길이인 7개의 단어 와 9 개의 음절, 8 개의 형태소로 동일하게 구성하였다. "Brown puppies that Bobby bought were big."은 구문적인 복잡성을 증가 시키기 위하여 문장 안에 관계사절을 포함한(Kleinow \& Smith, 2000; Usler et al., 2017) '길고 복잡한(complex-long, CL)' 문장이 다. 또 다른 문장은 "Puppies brown Bobby and big bought Bill”로 단어의 순서가 부적절한 길고 구문적 오류가 있는(faulty-long, $\mathrm{FL})^{\prime}$ 문장이었다. 이 문장은 구문적 오류로 인하여 말언어처리 및 말집행 시 더 많은 시간이 소요되어 조음속도에 영향을 미칠 것으로 예측하였다. 마지막으로 관계사절을 포함하지 않고 구 문적인 오류가 없는 ‘길고 단순한(simple-long, SL)' 문장인 "Bill and Bobby bought big brown puppies"를 포함하였다.

\subsection{2. 실험절차}

본 연구는 기관생명윤리위원회(Institutional Review Board)의 승인 하에 이루어졌다(IRB Protocol Number: 02011). 모든 참여 자는 연구의 목적과 실험절차에 대한 설명을 들은 후 서면동의 서에 서명을 하였으며, 참여자 선정기준에 부합하는지를 확인 하기 위한 검사를 실시한 후 실험에 참여하였다. 모든 실험은 소음이 없는 조용한 실험실에서 연구자와 참여자가 1 대 1 로 진 행하였다.

실험은 참여자가 의자에 앉아서 참여자로부터 $1.5 \mathrm{~m}$ 가량 떨 
어져 있는 컴퓨터 모니터(Dell, Round Rock, TX, USA) 화면에 나타나는 언어적 복잡성이 다른 문장을 보고 읽게 하는 방식으 로 이루어졌다. 각 참여자는 의자에 앉은 후 참여자의 발화를 녹음하기 위한 귀걸이형(behind-the-ear) 마이크를 착용하였다. 마이크는 참여자 입술의 오른쪽 끝부분에서 $2 \mathrm{~cm}$ 떨어진 곳에 고정되게 하였다.

참여자는 컴퓨터 모니터에 제시되는 언어적 복잡성이 다른 4 개의 문장을 한 셋트로 하여 총 15 개 세트를 읽었다. 각 셋트 내 에서 4 개의 언어적 복잡성이 다른 문장은 참여자에게 순서 없 이 무작위로 제시되었다(Smith et al., 2010). 문장과 문장 사이에 는 “+” 부호를 화면에 제시하여 참여자가 다음에 나올 문장을 읽을 준비를 하게 하였다. 본 연구는 각 참여자로부터 문장 별 10 개씩 총 40 개의 말 자료를 사용하고자 하였으나, 비유창성이 나 말 오류, 혹은 부적절한 쉼이 발생하여 분석에서 제외되는 말 자료가 발생할 가능성을 고려하여 문장별로 15 개의 말 자료 를 수집하였다.

연구자는 참여자에게 각 과제 문장을 읽을 때 자신에게 편안 한 말의 속도와 강도를 사용하여 평소대로 문장을 읽도록 하였 다. AWS의 경우 말 산출 시 유창성을 유지하기 위한 전략을 사 용하지 않도록 하였다. 각 참여자의 발화는 귀걸이형 마이크와 연결된 PowerLab Data Acquisition Systems(ADInstruments, http:// www.adinstruments.com)를 통해 녹음하여 .wav파일로 컴퓨터에 저장하였으며, 디지털캠코더(Canon Digital Video Camcorder, ZR800 NTSC)를 사용하여 참여자의 모든 실험과정을 녹화하였다.

\section{3. 자료분석}

\subsection{1. 말 자료 선택: 비유창성, 말 오류 및 쉼 분석}

본 연구는 유창하게 산출된 말 자료만을 사용하여 조음속도 를 분석하였다(Hall et al., 1999). 따라서 제 1저자는 녹음 및 녹 화하여 수집한 각각의 말 자료에 비유창성 및 말 오류가 있는지 확인하는 절차를 거쳤다. 즉, 산출한 말 자료에 정상적 비유창 성이나 비정상적 비유창성이 포함된 경우, 혹은 첨가나 생략, 대치, 왜곡과 같은 말 오류가 나타난 경우 그 자료는 분석에서 제외하였다. 또한, 조음속도 분석을 위하여 말 자료 내에 $250 \mathrm{~ms}$ 이상의 쉼이 포함된 경우(Andrews et al., 1982; Chon \& Lee, 2019; Chon et al., 2013; Hall et al., 1999) 혹은 문장을 읽을 때 참 여자가 한 호흡(호기)에 문장을 읽지 않아 중간에 쉼이 발생한 경우 그 자료 역시 분석에서 제외하였다. AWS의 경우, 7명으로 부터 17 개의 자료가 비유창성(6개), 말 오류(7개), 혹은 $250 \mathrm{~ms}$ 이상의 쉼(4개)으로 인하여 분석에서 제외되었다. 언어적 복잡 성 기준으로 SL 문장 3 개, $\mathrm{CL}$ 문장 4 개, $\mathrm{FL}$ 문장 10 개였다. 산출 순서별로 보면 분석에서 제외된 자료는 첫 번째 산출 문장 중 6 개, 두 번째 산출 문장 중 8 개, 세 번째 산출 문장 중 2 개, 네 번째 산출 문장 중 1 개였다. AWNS는 4명으로부터 4개의 자료(말 오 류 2 개, $250 \mathrm{~ms}$ 이상의 쉼 2개)가 분석에서 제외되었다. 언어적 복잡성 기준으로 SL 문장 3개, FL 문장 1개였으며, 문장산출 순 서별로 보면 첫 번째로 산출한 문장 중 2 개, 세 번째 산출 문장
중 1 개, 네 번째 산출 문장 중 1 개의 자료가 분석에서 제외되었 다. 비유창성, 말 오류 및 쉼과 관련한 분석을 통해 조음속도 분 석이 가능한 자료만을 선택한 후, 언어적 복잡성이 다른 문장별 로 대상자가 산출한 순서대로 말 자료 10 개씩을 선택하였다.

\subsection{2. 조음속도 분석}

조음속도는 선행연구들을 따라 유창하게 산출한 발화의 음 절수를 유창한 발화를 산출하는데 걸린 시간(초)으로 나누어 계 산하는 1초에 산출한 음절수(초당음절수)로 측정하였다(Chon et al., 2013; Hall et al., 1999). 대상자별로 각 언어적 복잡성 문장 에 따른 말 자료 10 개씩 총 40 개 말 자료의 조음속도 분석을 실 시하였다. 전술한대로 각 언어적 복잡성 문장의 음절 수는 $\mathrm{SS}$ 문장이 6개였으며, $\mathrm{SL}$ 문장, $\mathrm{CL}$ 문장, 그리고 $\mathrm{FL}$ 문장은 각각 9 개였다. Praat 프로그램(version 6.1.42; Boersma \& Weenink, 2021)을 사용하여 .wav 파일 형태로 저장된 각 말 자료의 문장 산출에 걸린 시간(초)을 측정하였으며, 각 문장의 음절수를 문 장 산출에 걸린 시간으로 나누어 조음속도를 계산하였다.

이후 (1) 언어적 복잡성 문장별로 10 개 말 자료를 사용하여 측정한 각 조음속도의 평균을 계산하여 언어적 복잡성별 전체 조음속도를 측정하였다. 또한 (2) 각 언어적 복잡성 문장에서 측 정한 10 개의 조음속도에서 첫 3 개 문장의 평균 조음속도, 중간 4 개 문장의 평균 조음속도, 마지막 3 개 문장의 평균 조음속도를 계산하여 문장산출 순서에 따른 조음속도를 측정하였다. 이는 문장산출 순서에 따른 조음속도의 대표성을 확보하기 위한 것 으로, 선행연구에서는 카테고리당 최소 2-3개 이상 발화의 조 음속도를 평균 내어 사용하였기 때문이다(Chon et al., 2012; Chon \& Lee, 2016).

\section{4. 신뢰도 측정}

본 연구의 종속변수인 조음속도의 평가자 간 신뢰도를 측정 하기 위하여 전체 22 명의 자료 중 $14 \%(3$ 명)를 임의로 선정하였 다. 평가자 간 신뢰도는 본 연구의 제 1 저자와 제 1 저자에게 비 유창성 분석 및 조음속도 분석에 대한 훈련을 받은 언어병리학 전공 평가자에 의하여 독립적으로 이루어졌다. 본 연구는 전체 조음속도와 말 산출 순서에 따른 조음속도를 계산하기 위하여 각 연구 참여자로부터 언어적 복잡성 별 10 개(총 40개) 말 자료 의 조음속도를 각각 측정하였기 때문에 평가자 간 신뢰도는 3 명의 말 자료 120 개의 조음속도 측정값을 사용하였다. 신뢰도 분석은 피어슨 상관계수를 사용하여 이루어졌으며, $\mathrm{SS}$ 의 상관 계수는 $.94, \mathrm{SL}$ 의 상관계수는 $.95, \mathrm{CL}$ 의 상관계수는 $.92, \mathrm{FL}$ 의 상 관계수는 .95로 나타났다.

\section{5. 자료의 통계처리}

본 연구의 통계분석을 위하여 IBM SPSS Statistics ver. 26을 사용하였다. 각 집단별로 대상자가 11 명이었기 때문에 종속변 수(조음속도)가 모수 검정이 가능한지 확인하기 위하여 ShapiroWilk 검정을 실시하였다. 그 결과, 각 집단의 언어적 복잡성에 따른 전체 조음속도가 모두 정규분포를 만족하는 것으로 나타 
났다(각각 $p>.05)$. 각 집단의 언어적 복잡성 내 문장산출 순서에 따른 조음속도 역시 모두 정규분포를 만족하였다(각각 $p>.05$ ).

$\mathrm{AWS}$ 와 AWNS 간에 언어적 복잡성에 따른 전체 조음속도에 차이가 있는지 확인하기 위하여 2요인 혼합설계분산분석(2 way mixed-design ANOVA)을 실시하였다. 이때 집단 간 요인은 말더듬 장애 유무에 따른 집단(AWS, AWNS)이었으며, 집단 내 요인은 언어적 복잡성에 따른 문장(SS, SL, CL, FL)이었다. 유의 미한 주효과 발생 시 Bonferroni 사후검정을 실시하였다. 두 번 째 연구문제인 집단, 언어적 복잡성, 그리고 문장산출 순서에 따른 조음속도의 차이를 확인하기 위하여 3요인 혼합설계분산 분석(3 way mixed-design ANOVA)을 실시하였다. 집단 간 요인 은 말더듬 장애 유무에 따른 집단이었으며, 집단 내 요인은 언 어적 복잡성에 따른 문장과 문장산출 순서(첫 3 개 문장, 중간 4 개 문장, 마지막 3 개 문장)였다. 또한, 언어적 복잡성과 문장산 출 순서에서 유의미한 상호작용이 발생하여 추가적으로 각 언 어적 복잡성 문장별로 반복측정분산분석(repeated measures ANOVA)을 실시하였으며, Bonferroni 사후검정을 실시하였다.

\section{3. 연구결과}

3.1. 집단과 언어적 복잡성에 따른 조음속도 비교 결과

언어적 복잡성에 따른 AWS와 AWNS의 조음속도 자료의 분 포는 그림 1 에 상자그림으로 제시하였으며, 전체 조음속도의 평균과 표준편차는 표 1 에 제시하였다. 조음속도의 분포 및 평 균은 언어적 복잡성과 상관없이 $\mathrm{AWS}$ 가 $\mathrm{AWNS}$ 에 비하여 상대 적으로 느린 것으로 나타났다. 또한 SS 문장의 평균 조음속도가 긴 문장들의 평균 조음속도보다 상대적으로 빠른 것으로 나타 났다.

\section{표 1. 언어적 복잡성에 따른 $\mathrm{AWS}$ 와 $\mathrm{AWNS}$ 의 조음속도의 평균과 표준편차}

Table 1. Mean articulation rates $( \pm \mathrm{SD})$ of AWS and AWNS across the linguistic complexity conditions

\begin{tabular}{c|c|c|c|c}
\hline \multirow{2}{*}{ Group } & \multicolumn{4}{|c}{ Linguistic complexity (sentence) } \\
\cline { 2 - 5 } & Simple-short & Simple-long & Complex-long & Faulty-long \\
\hline AWS & $5.16( \pm .49)$ & $3.94( \pm .34)$ & $4.16( \pm .42)$ & $3.78( \pm .40)$ \\
\hline AWNS & $5.63( \pm .38)$ & $4.36( \pm .32)$ & $4.77( \pm .33)$ & $4.37( \pm .37)$ \\
\hline AWS, adults who stutter; AWNS, adults who do not stutter.
\end{tabular}

집단과 언어적 복잡성에 따른 조음속도의 차이를 확인하기 위하여 2 요인 $(2 \times 4)$ 혼합설계분산분석을 실시하였다. Mauchly의 구형성검정 결과, 언어적 복잡성 요인이 구형성가정을 만족하지 못하였기 때문에 $\left(W=.195, \chi^{2}(5)=30.628, p<.001\right)$ Greenhouse-Geisser 결과 값을 사용하였다. 분석 결과, 집단과 언어적 복잡성 간 상호 작용은 유의하지 않은 것으로 나타났다 $[F(1.528,30.561)=1.204$, $p>.05]$. 집단의 경우 유의한 주효과가 나타났다 $[F(1,20)=12.867$, $p<.01$, partial $\left.\eta^{2}=.391\right]$. 즉, AWS가 AWNS보다 평균 전체 조음속 도가 유의하게 느린 것으로 나타났다. 언어적 복잡성 역시 유의한 주 효과가 나타났다 $\left[F(1.528,30.561)=198.418, p<.001\right.$, partial $\left.\eta^{2}=.908\right]$.
Bonferroni 사후검정 결과, SS 문장이 긴 문장들보다 평균 조음 속도가 유의하게 빨랐으며 (각각 $p<.001$ ), $\mathrm{CL}$ 문장이 $\mathrm{SL}$ 문장 $(p<.001)$ 및 $\mathrm{FL}$ 문장 $(p<.001)$ 보다 평균 조음속도가 유의하게 빠 른 것으로 나타났다( $\mathrm{SS}$ 문장>CL 문장> $\mathrm{SL}$ 문장 $\approx \mathrm{FL}$ 문장).

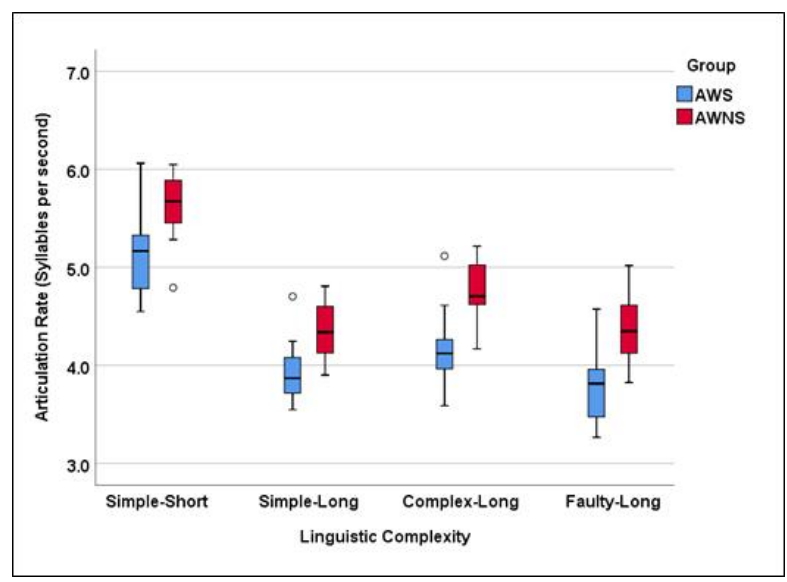

AWS, adults who stutter; AWNS, adults who do not stutter.

그림 1. 언어적 복잡성에 따른 AWS와 AWNS간 조음속도 상자그림

Figure 1. Box plots comparing the articulation rates between AWS and AWNS across the linguistic complexity conditions

3.2. 집단, 언어적 복잡성 및 문장산출 순서에 따른 조음속도 비교 결과

집단, 언어적 복잡성 및 문장산출 순서에 따른 조음속도의 기 술통계 결과는 표 2 와 같다. 전반적으로 모든 언어적 복잡성 과 제와 문장산출 순서에서 AWS가 AWNS보다 평균 조음속도가 느린 경향을 보였다. 또한 두 집단은 모두 첫 3 개 문장의 평균 조음속도가 중간 4 개 문장과 마지막 3 개 문장의 평균 조음속도 보다 상대적으로 느린 모습을 보였다.

집단과 언어적 복잡성 및 문장산출 순서에 따른 조음속도의 차이를 검증하기 위하여 3 요인 $(2 \times 4 \times 3)$ 혼합설계분산분석을 실 시하였다. Mauchly의 구형성검정 결과, 언어적 복잡성 요인과 문장산출 순서 요인 및 두 요인의 상호작용이 구형성가정을 만 족하지 못하였기 때문에(언어적 복잡성: $W=.204, \chi^{2}(5)=29.771$, $p<.001$; 문장산출 순서: $W=.551, \chi^{2}(2)=11.322, p<.01$; 언어적 복 잡성 $\times$ 문장산출 순서: $\left.W=.135, \chi^{2}(20)=35.535, p<.05\right)$ GreenhouseGeisser 결과 값을 사용하였다. 분석 결과, 집단 간 유의한 주효 과가 나타났다 $\left[F(1,20)=12.603, p<.01\right.$, partial $\left.\eta^{2}=.387\right]$. 즉, 전체 조음속도의 평균을 비교했던 결과와 동일하게 AWNS가 AWS 보다 유의하게 빠른 평균 조음속도를 보였다. 집단 요인은 다른 요인들과 유의한 상호작용이 나타나지 않았다(집단×언어적 복 잡성: $F(3,60)=1.250, p>.05$; 집단 $\times$ 문장산출 순서: $F(2,40)=.755$, $p>.05$; 집단 $\times$ 언어적 복잡성 $\times$ 문장산출 순서: $F(6,120)=1.677$, $p>.05$ ).

언어적 복잡성 요인과 문장산출 순서 요인 역시 유의한 주효 과가 나타났으나(언어적 복잡성: $F(1.550,30.994)=201.318$, $p<.001$, partial $\eta^{2}=.910$; 문장산출 순서: $F(1.380,27.607)=32.175$, 
표 2. 언어적 복잡성과 문장산출 순서에 따른 집단 간 조음속도의 평균과 표준편차

Table 2. Mean articulation rates $( \pm \mathrm{SD})$ of AWS and AWNS across the linguistic complexity conditions and trials

\begin{tabular}{c|c|c|c|c|c}
\hline \multirow{2}{*}{ Group } & \multirow{2}{*}{ Trials } & \multicolumn{4}{|c}{ Linguistic complexity (sentence) } \\
\cline { 2 - 6 } & & Simple-short & Simple-long & Complex-long & Faulty-long \\
\hline \multirow{3}{*}{ AWS } & First 3 productions & $4.87( \pm .43)$ & $3.78( \pm .32)$ & $4.07( \pm .41)$ & $3.56( \pm .42)$ \\
\cline { 2 - 6 } & Middle 4 productions & $5.23( \pm .52)$ & $3.98( \pm .35)$ & $4.18( \pm .37)$ & $3.84( \pm .40)$ \\
\cline { 2 - 6 } & Last 3 productions & $5.34( \pm .63)$ & $4.05( \pm .42)$ & $4.22( \pm .54)$ & $3.90( \pm .41)$ \\
\hline \multirow{3}{*}{ AWNS } & First 3 productions & $5.34( \pm .27)$ & $4.22( \pm .26)$ & $4.54( \pm .23)$ & $4.10( \pm .36)$ \\
\cline { 2 - 6 } & Middle 4 productions & $5.81( \pm .45)$ & $4.43( \pm .39)$ & $4.88( \pm .39)$ & $4.43( \pm .40)$ \\
\cline { 2 - 6 } & Last 3 productions & $5.67( \pm .56)$ & $4.41( \pm .39)$ & $4.86( \pm .42)$ & $4.55( \pm .41)$ \\
\hline
\end{tabular}

AWS, adults who stutter; AWNS, adults who do not stutter.

$p<.001$, partial $\left.\eta^{2}=.617\right)$ 두 요인 간에 유의한 상호작용이 나타났 다 $\left[F(3.252,65.035)=2.753, p<.05\right.$, partial $\left.\eta^{2}=.121\right]$. 전반적으로 $\mathrm{SS}$ 문장의 평균 조음속도가 가장 빠르고 $\mathrm{CL}$ 문장이 두 번째로 평균 조음속도가 빨랐으며, SL 문장과 $\mathrm{FL}$ 문장의 평균 조음속 도에는 큰 차이가 없었다. 하지만, 그림 2에 보여지는 것과 같이 $\mathrm{SS}$ 문장, $\mathrm{SL}$ 문장, $\mathrm{CL}$ 문장은 모두 첫 3 개 문장의 평균 조음속도 가 느리고, 중간 4 개 문장과 마지막 3 개 문장의 평균 조음속도 가 비슷하였으나, FL 문장의 경우, 중간 4 개 문장의 평균 조음속 도가 마지막 3 개 문장의 평균 조음속도보다 느린 것으로 나타 났다. 이를 확인하기 위하여 추가적으로 집단을 구별하지 않고 각 언어적 복잡성 문장별로 문장산출 순서에 따른 조음속도를 확인하기 위하여 반복측정 분산분석을 실시하였다. 구형성가 정을 만족하지 못하는 경우 Greenhouse-Geisser 결과 값을 사용 하였다.

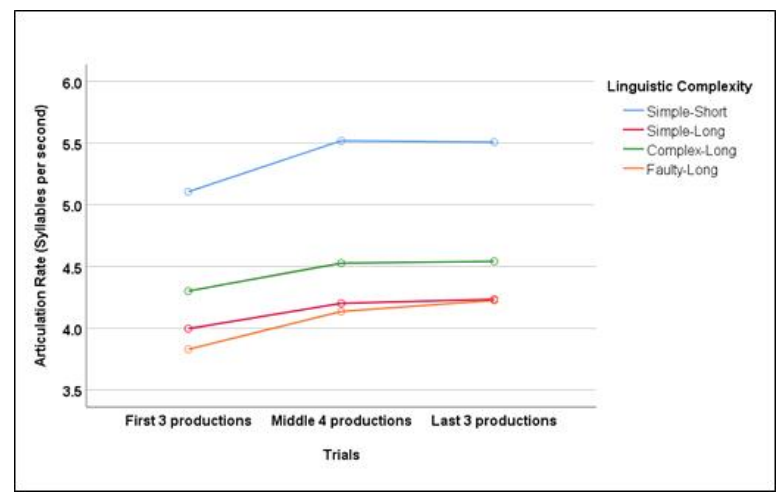

그림 2. 언어적 복잡성과 문장산출 순서의 상호작용 그래프

Figure 2. Interaction graphs of the linguistic complexity and trials

$\mathrm{SS}$ 문장은 문장산출 순서에 따른 평균 조음속도가 동일하지 않은 것으로 나타났다 $\left[F(2,42)=15.170, p<.001\right.$, partial $\left.\eta^{2}=.419\right]$. Bonferroni 사후검정 결과 첫 3 개 문장이 중간 4 개 문장 $(p<.001)$ 과 마지막 3 개 문장 $(p<.01)$ 보다 평균 조음속도가 유의하게 느린 것으로 나타났다. 중간 4개 문장과 마지막 3 개 문장의 평균 조 음속도는 유의한 차이가 없었다( $p>.05)$. SL 문장도 SS 문장과 동일한 패턴이 나타났다. 문장산출 순서에 따라 평균 조음속도 가 유의하게 다른 것으로 나타났고 $[F(2,42)=10.596, p<.001$, partial $\eta^{2}=$.335], Bonferroni 사후검정 결과 첫 3 개 문장이 중간 4 개 문장과 마지막 3 개 문장의 평균 조음속도보다 유의하게 느
린 것으로 나타났으며(각각 $p<.01$ ), 중간 4 개 문장과 마지막 3 개 문장 간에는 유의한 차이가 없었다 $(p>.05) . \mathrm{CL}$ 문장 역시 문장 산출 순서에 따른 평균 조음속도에 유의한 차이를 보였으며 $\left[F(1.586,33.309)=14.152, p<.001\right.$, partial $\left.\eta^{2}=.403\right]$, Bonferroni 사 후검정 결과 첫 3 개 문장의 평균 조음속도가 중간 4 개 문장과 마지막 3 개 문장의 평균 조음속도보다 유의하게 느렸고(각각 $p<.01)$ 중간 4 개 문장과 마지막 3 개 문장의 평균 조음속도는 비 슷한 것으로 나타났다( $p>.05)$. 즉, $\mathrm{SS}, \mathrm{SL}, \mathrm{CL}$ 문장의 조음속도 는 첫 3 개 문장<중간 4 개 문장 $\approx$ 마지막 3 개 문장이었다.

$\mathrm{FL}$ 문장은 문장산출 순서에 따른 평균 조음속도에 유의한 차 이를 보였으며 $\left[F(1.479,31.051)=48.459, p<.001\right.$, partial $\left.\eta^{2}=.698\right]$, Bonferroni 사후검정 결과 다른 문장들과 마찬가지로 첫 3 개 문 장이 중간 4 개 문장 $(p<.001)$ 및 마지막 3 개 문장 $(p<.001)$ 의 평균 조음속도보다 유의하게 느렸다. 하지만 중간 4 개 문장의 평균 조음속도가 마지막 3 개 문장의 평균 조음속도보다 유의하게 느 린 것으로 나타났다 $(p<.05)$ (첫 3 개 문장<중간 4 개 문장<마지막 3 개 문장).

\section{4. 논의 및 결론}

본 연구는 조음속도를 사용하여 AWS의 말운동통제 능력과 운동기술 학습 능력을 AWNS와 비교하는 것을 목적으로 하였 으며, 과제 문장의 길이와 복잡성이 조음속도에 미치는 영향을 살피고자 하였다. 연구 결과 (1) 언어적 복잡성을 달리한 문장 4 개 모두에서 $\mathrm{AWS}$ 는 $\mathrm{AWNS}$ 보다 전체 조음속도가 유의하게 느 린 것으로 나타났다. 또한 짧고 단순한 문장(SS)의 조음속도가 긴 문장들보다 빨랐으며, 긴 문장들 중에서는 관계사절을 포함 하여 구문적으로 복잡한 문장 $(\mathrm{CL})$ 이 관계사절을 포함하지 않은 문장(SL)과 구문적인 오류가 있는 문장(FL)보다 조음속도가 빠 른 것으로 나타났다. (2) 언어적 복잡성과 문장산출 순서에 상관 없이 AWS가 AWNS보다 유의하게 느린 조음속도를 보였으며, 두 집단 모두 문장산출 순서에 따른 연습효과가 나타났다. 모든 문장에서 중간 4개 문장과 마지막 3개 문장의 조음속도가 첫 3 개 문장의 조음속도보다 빨랐다. SS, SL, CL 문장의 경우 중간 4 개 문장의 조음속도와 마지막 3 개 문장의 조음속도에 차이가 없었던 반면, FL 문장은 중간 4개 문장의 조음속도보다 마지막 3 개 문장의 조음속도가 유의하게 빠른 것으로 나타났다. 
4.1. 집단과 언어적 복잡성에 따른 조음속도

$\mathrm{AWS}$ 의 조음속도가 AWNS보다 전반적으로 느렸던 결과는 $\mathrm{AWS}$ 의 말운동통제 능력이 상대적으로 미숙하거나 AWNS와는 다름을 시사한다. 이는 운동적인 방법을 통하여 AWS가 AWNS 보다 말운동안정성이 낮거나 말운동 기술이 제한되어 있다고 보고한 선행연구들의 결과와 맥락을 같이 한다고 할 수 있다 (Bauerly \& De Nil, 2011; Kleinow \& Smith, 2010). 반면 본 연구는 AWS가 AWNS보다 빠른 조음속도를 보였다고 하였던 Bauerly et al.(2019)과는 상반된 결과가 나타났다. 하지만 이는 실험 설계 상의 차이로 인한 것일 수 있다. Bauerly et al.(2019)은 사회적 스 트레스 상황과 비 스트레스 상황을 사용하여 집단 간 조음속도 를 비교하였다. 연구 참여자는 5 분간 독백 과제를 수행하였는 데, 비 스트레스 상황은 자신이 원하는 직업에 대해 말하는 것 이었으며, 사회적 스트레스 상황은 자신이 원하는 직업에 왜 자 신이 적합한 사람인가를 발표하는 것이었다. 이 연구에서 사용 한 과제는 자발화 과제이기 때문에 연구 참여자들이 산출한 발 화의 길이 및 구문적인 복잡성이 통제되지 않았다. 문장의 길이 및 복잡성에 따른 조음속도가 유의미한 차이를 보였던 본 연구 의 결과를 근거로 한다면 독백 상황에서 AWS와 AWNS의 다양 한 발화 길이와 복잡성은 조음속도에 영향을 주었을 가능성이 높다. 또한 말더듬는 사람이 길고 복잡한 발화를 산출할 때 비 정상적 비유창성의 가능성이 높아지는 것을 고려한다면(Buhr \& Zebrowski, 2009; Lee \& Sim, 2015) 독백과제 시 비유창성의 가능성을 낮추기 위하여 AWS가 상대적으로 짧고 단순한 발화 를 산출했을 수도 있으며 이러한 결과가 빠른 조음속도를 유발 했을 수도 있을 것이다. 마지막으로 연구자들이 주장한대로 연 구에 참여하였던 AWS는 불안 지수(상태불안 및 특성불안)가 AWNS보다 유의하게 높은 것으로 나타났으며, 높은 불안 수준 으로 인해 AWS의 조음속도가 평소보다 증가했을 수도 있음을 예측해볼 수 있다(Bauerly et al., 2019; Goberman et al., 2011).

집단 간 차이뿐 아니라 문장의 길이와 복잡성 또한 조음속도 에 영향을 주는 요인이었다. 본 연구는 두 집단 모두 $\mathrm{SS}$ 문장의 조음속도가 가장 빨랐으며, 길이가 긴 문장의 경우 구문적인 복 잡성이나 오류의 유무가 일정한 패턴을 보이지 않았다. 선행연 구들은 발화의 길이와 복잡성이 조음속도에 영향을 미치는 화 자 내 요인이라고 하였으나 그 결과는 다양하였다(Darling-White \& Banks, 2021; Howell et al., 1999). Howell et al.(1999)은 독백과 제를 통해 수집한 자발화를 운율단위(tone unit)를 기준으로 나 눈 후 조음속도를 분석한 결과 $\mathrm{AWS}$ 는 운율단위에 포함된 단어/ 음절의 수가 증가할수록 조음속도가 증가하였다고 보고하였다. 하지만, 세부적으로 운율단위 내에 포함된 단어나 음절의 수가 일정 수준을 넘어서게 되면, 즉, 대략 5 개 단어 수 혹은 5 개 음절 수 이상의 운율단위부터는 조음속도의 증가가 나타나지 않았 다. 또한 독백과제의 특성상 구문적 복잡성은 통제되지 않았다. 본 연구의 경우 기준 문장인 SS 문장이 4개의 단어(6개 음절)로 이루어져 있었으며 길고 구문적 복잡성이 다양한 문장은 7개 단어(9개 음절)로 이루어져 있었다. 따라서 Howell et al.(1999) 이 보고한 짧은 단어/음절 수로 이루어진 운율단위에서 나타난
조음속도의 증가와 비교하는 것은 적절치 않을 것이다. DarlingWhite \& Banks(2021)의 경우, 10-14세 일반 아동에게 2-7개 단 어로 이루어진 6 개 문장을 산출하게 하여 문장 길이에 따른 조 음속도를 비교한 결과, 대체적으로 문장의 길이가 길어질수록 조음속도가 빨라졌다고 하였다. 이 결과를 성인을 대상으로 한 본 연구의 결과와 직접적인 비교를 하기는 한계가 있지만 Darling-White \& Banks(2021) 역시 문장 길이의 증가에 초점을 맞추었으며 언어적 복잡성은 고려하지 않았다. 또한 연구자들 역시 일정 수준까지는 문장 길이가 길수록 조음속도가 증가하 는 모습을 보이지만 그 수준을 지나게 되면 다시 감소하는 양상 을 보일 것으로 예측하였다. 선행연구들과 본 연구의 결과를 종 합하면 한 호흡(호기)에 발화를 산출할 때 화자는 조음기관의 움직임의 속도를 다양하게 조절하게 되며, 일정 수준까지는 산 출하려고 하는 발화의 길이가 길어질수록 조음속도 역시 증가 하는 양상을 보인다고 생각할 수 있다. 하지만 그 수준을 넘어 서게 되면 발화의 길이와 복잡성의 증가는 인지 및 말언어처리 과정에 부담을 주게 될 것이며, 화자는 자신이 계획한 발화를 정확하게 산출하기 위하여 조음기관의 움직임의 속도를 융통 성 있게 감소시키는 것으로 해석할 수 있을 것이다.

$\mathrm{AWS}$ 와 AWNS 모두 긴 문장 3 개 중 구문적 복잡성을 증가시 키기 위하여 관계사절을 포함했던 문장 $(\mathrm{CL})$ 의 조음속도가 관계 사절을 포함하지 않았던 문장(SL)의 조음속도보다 상대적으로 빨랐던 것은 선행연구와는 다른 결과였다. 운동적인 방법을 사 용하였던 선행연구들은 대체적으로 구문적으로 복잡한 발화가 단순한 발화보다 말운동안정성이 낮다고 보고하였기 때문이다 (Kleinow \& Smith, 2000; Usler et al., 2017). 본 연구에서 따로 측 정하여 비교하지는 않았지만 본 연구에 참여하였던 다수의 연 구 참여자들은 $\mathrm{CL}$ 문장 산출 시 전체적인 문장의 운율을 따르 며 관계사절 "Bobby bought"를 문장 내 다른 단어들보다 빠르게 발음하는 모습을 보였다. 이는 조음기관의 움직임이 운율적인 측면의 영향을 받아 문장 내에서 조정될 수 있음을 예측하게 한 다. 하지만 문장의 운율적 측면이 조음속도에 영향을 주는 요인 인지, 영향을 준다면 어떠한 방식으로 영향을 주는지에 대한 것 을 밝히기 위해서는 추후 연구가 필요할 것이다.

\section{2. 문장산출 순서의 영향}

전체 조음속도 결과와 마찬가지로 $\mathrm{AWS}$ 는 문장산출 순서와 상관없이 AWNS보다 조음속도가 일관되게 느렸으나 문장산출 순서에 따른 연습효과, 즉 조음속도가 증가하는 모습이 나타났 다. 또한, 조음속도의 변화는 두 집단이 비슷한 패턴을 보이는 것으로 나타났다. 중간 4 개 문장 및 마지막 3 개 문장이 첫 3 개 문장보다 조음기관의 움직임의 속도가 증가한 것은 연구 참여 자들이 반복적인 문장산출을 통하여 운동기술 학습이 나타난 것으로 해석할 수 있다. 이는 운동적 방법을 사용하여 연습효과 를 살핀 선행연구들의 결과와 맥락을 같이한다(Sasisekaran \& Weisberg, 2014; Smith et al., 2010). 본 연구는 문장산출 순서를 세 부분으로 나누어 비교를 하였는데, 구문적으로 적절했던 문 장들, 즉, $\mathrm{SS}, \mathrm{SL}, \mathrm{CL}$ 문장은 중간 4 개 문장과 마지막 3 개 문장의 
조음속도 간 차이가 없는 것으로 나타나 연습효과의 상한이 나 타나고 유지되는 것을 알 수 있었다. 반면 $\mathrm{FL}$ 은 여전히 연습효 과가 발생하여 마지막 3 개 문장의 조음속도가 중간 4 개 문장의 조음속도보다 유의하게 빠른 것으로 나타났다. 이는 구문 오류 문장 산출을 위한 말언어처리 및 말집행 과정과 운동학습 과정 이 구문적으로 적절한 문장들에 비하여 상대적으로 오래 걸리 는 것으로 해석할 수 있을 것이다. 문장 간 전체 조음속도를 비 교하였을 때에도 $\mathrm{FL}$ 문장이 상대적으로 느린 조음속도를 보였 던 결과까지 고려한다면 구문적인 측면이 조음속도에 영향을 끼치는 화자 내 요인임을 다시 한번 확인할 수 있었다.

본 연구는 음향적 방법인 조음속도를 사용하여 AWS와 AWNS의 특성을 비교하는 것이 목적이었으므로 행동적 방법은 고려사항이 아니었다. 하지만 연구방법에서 기술하였듯이 조 음속도 분석을 위한 말 자료 선정 과정에서 AWS가 AWNS보다 비유창성, 말 오류 및 $250 \mathrm{~ms}$ 이상 긴 쉼의 빈도가 4 배 이상 높게 나타나(AWS 17회, AWNS 4회) 행동적 방법을 사용하였던 선행 연구 결과와 동일한 모습을 보였다(Sasisekaran \& Weisberg, 2014). 비유창성, 말 오류 및 쉼은 두 집단 모두 긴 문장을 산출 하는 과정에서 관찰되었으며, AWS는 특히 FL 문장과 CL 문장 에서 이러한 모습이 빈번하게 나타났다. 또한 AWS에게서 관찰 된 비유창성, 말 오류와 쉼 총 17회 중 16회는 첫 번째(6개), 두 번째(8개) 혹은 세 번째(2개)로 산출한 문장에서 관찰되었다. 이 문장들은 모두 조음속도 분석에서 제외되었으므로 문장별 전 체 조음속도 및 문장산출 순서에 따른 조음속도 분석 시 AWS 는 AWNS보다 상대적으로 후반부에 산출한 말 자료가 더 많이 포함되었으며, 그럼에도 불구하고 AWS의 조음속도는 AWNS 보다 일관되게 느림을 확인할 수 있었다. 이러한 모습들은 AWS 의 말운동통제 능력이 AWNS보다 상대적으로 미숙하거나 불안 정하며, 언어적인(구문적인) 측면이 $\mathrm{AWS}$ 의 말운동 시스템에 영향을 미쳐 말 붕괴를 일으킬 수 있다고 주장한 역동적-다중요 인모델(Smith \& Kelly, 1997; Smith \& Weber, 2017)을 지지하는 결과라고 할 수 있을 것이다. 추후 연구에서 음향적 분석, 운동 적 분석 및 행동적 분석을 위한 변수들을 다양하게 사용하여 AWS의 말운동통제 능력을 살핀다면 말더듬는 사람의 말 특성 을 보다 포괄적으로 이해하는데 도움이 될 것으로 보인다.

\section{3. 결론}

본 연구는 조음속도를 사용하여 AWS와 AWNS의 말운동통 제 능력과 운동기술 학습능력을 비교하였으며, 이를 위해 길이 와 구문적 복잡성을 통제한 문장을 사용하였다. 연구 결과를 통 하여 AWS의 말운동통제 능력이 AWNS보다 상대적으로 미숙 하거나 AWNS와는 다름을 확인할 수 있었으며, 말 산출을 위한 운동기술 학습 패턴, 즉, 연습효과가 나타나고 상한까지 도달하 는 패턴은 $\mathrm{AWNS}$ 와 비슷한 것을 알 수 있었다. 또한 과제의 길 이와 복잡성은 인지, 언어처리과정 및 말 산출 계획에 부담을 주기 때문에 말운동통제와 운동기술 학습에 영향을 미치는 요 인이라고 보고한 선행연구들의 결과를 재확인할 수 있었다.

\section{References}

Ahn, J. B., Shin, M. S., \& Kwon, D. H. (2002). The study of speech rate in normal-speaking adults and children. Speech Sciences, 9(4), 93-103.

Amir, O., \& Grinfeld, D. (2011). Articulation rate in childhood and adolescence: Hebrew speakers. Language and Speech, 54(2), 225-240.

Andrews, G., Howie, P. M., Dozsa, M., \& Guitar, B. E. (1982). Stuttering: Speech pattern characteristics under fluency-inducing conditions. Journal of Speech and Hearing Research, 25(2), 208-216.

Bauerly, K. R., \& De Nil, L. F. (2011). Speech sequence skill learning in adults who stutter. Journal of Fluency Disorders, 36(4), 349-360.

Bauerly, K. R., Jones, R. M., \& Miller, C. (2019). Effects of social stress on autonomic, behavioral, and acoustic parameters in adults who stutter. Journal of Speech, Language, and Hearing Research, 62(7), 2185-2202.

Boersma, P., \& Weenink, D. (2021). Praat: Doing phonetics by computer (version 6.1.42) [Computer software]. Retrieved from http://www.praat.org/

Buhr, A. P., \& Zebrowski, P. M. (2009). Sentence position and syntactic complexity of stuttering in early childhood: A longitudinal study. Journal of Fluency Disorders, 34(3), 155-172.

Chon, H., Kraft, S. J., Zhang, J., Loucks, T., \& Ambrose, N. G. (2013). Individual variability in delayed auditory feedback effects on speech fluency and rate in normally fluent adults. Journal of Speech, Language, and Hearing Research, 56(2), 489-504.

Chon, H., \& Lee, S. B. (2016). Effects of stuttering severity on articulation rate in fluent and dysfluent utterances of preschool children who stutter. Phonetics and Speech Sciences, 8(3), 79-90.

Chon, H., \& Lee, S. B. (2019). Characteristics of speech rates and utterance lengths in fluent and disfluent utterances of adults who stutter. Audiology and Speech Research, 15(3), 214-222.

Chon, H., Sawyer, J., \& Ambrose, N. G. (2012). Differences of articulation rate and utterance length in fluent and disfluent utterances of preschool children who stutter. Journal of Communication Disorders, 45(6), 455-467.

Darling-White, M., \& Banks, S. W. (2021). Speech rate varies with sentence length in typically developing children. Journal of Speech, Language, and Hearing Research, 64(6S), 2385-2391.

de Andrade, C. R. F., Cervone, L. M., \& Sassi, F. C. (2003). Relationship between the stuttering severity index and speech rate. Sao Paulo Medical Journal, 121(2), 81-84.

Dunn, L. M., \& Dunn, L. M. (1997). Peabody picture vocabulary test-third edition (PPVT-III). Circle Pines, MN: American Guidance Service. 
Goberman, A. M., Hughes, S., \& Haydock, T. (2011). Acoustic characteristics of public speaking: Anxiety and practice effects. Speech Communication, 53(6), 867-876.

Hall, K. D., Amir, O., \& Yairi, E. (1999). A longitudinal investigation of speaking rate in preschool children who stutter. Journal of Speech, Language, and Hearing Research, 42(6), 1367-1377.

Howell, P., Au-Yeung, J., \& Pilgrim, L. (1999). Utterance rate and linguistic properties as determinants of lexical dysfluencies in children who stutter. The Journal of the Acoustical Society of America, 105(1), 481-490.

Jacewicz, E., Fox, R. A., O’Neill, C., \& Salmons, J. (2009). Articulation rate across dialect, age, and gender. Language Variation and Change, 21(2), 233-256.

Jacewicz, E., Fox, R. A., \& Wei, L. (2010). Between-speaker and within-speaker variation in speech tempo of American English. Journal of the Acoustical Society of America, 128(2), 839-850.

Kleinow, J., \& Smith, A. (2000). Influences of length and syntactic complexity on the speech motor stability of the fluent speech of adults who stutter. Journal of Speech, Language, and Hearing Research, 43(2), 548-559.

Kloth, S. A. M., Janssen, P., Kraaimaat, F. W., \& Brutten, G. J. (1995). Speech-motor and linguistic skills of young stutterers prior to onset. Journal of Fluency Disorders, 20(2), 157-170.

Lee, S., \& Sim, H. (2015). A longitudinal study of utterance length in morphemes as a predictor of treatment outcome in early childhood stuttering. Communication Sciences \& Disorders, 20(2), 189-201.

Logan, K. J., Byrd, C. T., Mazzocchi, E. M., \& Gillam, R. B. (2011). Speaking rate characteristics of elementary-school-aged children who do and do not stutter. Journal of Communication Disorders, 44(1), 130-147.

Maner, K. J., Smith, A., \& Grayson, L. (2000). Influences of utterance length and complexity on speech motor performance in children and adults. Journal of Speech, Language, and Hearing Research, 43(2), 560-573.

Manning, W. H. (2010). Clinical decision making in fluency disorders (3rd ed.). Clifton Park, NY: Delmar Cengage Learning.

Meyers, S. C., \& Freeman, F. J. (1985). Interruptions as a variable in stuttering and disfluency. Journal of Speech and Hearing Research, 28(3), 428-435.

Park, J., \& Kwon, D. (2010). According to the severity of stuttering adults of speed rate characteristics comparison study. Journal of Special Education: Theory and Practice, 11(1), 129-146.

Park, J., Oh, S., Jun, J. P., \& Kang, J. S. (2015). Effects of background noises on speech-related variables of adults who stutter. Phonetics and Speech Sciences, 7(1), 27-37.

Postma, A., \& Kolk, H. (1993). The covert repair hypothesis: Prearticulatory repair processes in normal and stuttered disfluencies. Journal of Speech and Hearing Research, 36(3), 472-487.
Quené, H. (2008). Multilevel modeling of between-speaker and within-speaker variation in spontaneous speech tempo. The Journal of the Acoustical Society of America, 123(2), 1104-1113.

Sadagopan, N., \& Smith, A. (2008). Developmental changes in the effects of utterance length and complexity on speech movement variability. Journal of Speech, Language, and Hearing Research, 51(5), 1138-1151.

Sasisekaran, J. (2012). Effects of delayed auditory feedback on speech kinematics in fluent speakers. Perceptual and Motor Skills, 15(3), 845-864.

Sasisekaran, J., \& Weisberg, S. (2014). Practice and retention of nonwords in adults who stutter. Journal of Fluency Disorders, 41, $55-71$.

Smith, A., \& Kelly, E. (1997). Stuttering: A dynamic, multifactorial model. In R. Curlee \& G. Siegel (Eds.), Nature and treatment of stuttering: New directions (2nd ed., pp. 204-217). Needham Heights, MA: Allyn \& Bacon.

Smith, A., Sadagopan, N., Walsh, B., \& Weber-Fox, C. (2010). Increasing phonological complexity reveals heightened instability in inter-articulatory coordination in adults who stutter. Journal of Fluency Disorders, 35(1), 1-18.

Smith, A., \& Weber, C. (2017). How stuttering develops: The multifactorial dynamic pathways theory. Journal of Speech, Language, and Hearing Research, 60(9), 2483-2505.

Smits-Bandstra, S., De Nil, L. F., \& Saint-Cyr, J. A. (2006). Speech and nonspeech sequence skill learning in adults who stutter. Journal of Fluency Disorders, 31(2), 116-136.

Usler, E., Smith, A., \& Weber, C. (2017). A lag in speech motor coordination during sentence production is associated with stuttering persistence in young children. Journal of Speech, Language, and Hearing Research, 60(1), 51-61.

Usler, E. R., \& Walsh, B. (2018). The effects of syntactic complexity and sentence length on the speech motor control of school-age children who stutter. Journal of Speech, Language, and Hearing Research, 61(9), 2157-2167.

Williams, K. T. (1997). Expressive vocabulary test (EVT). Circle Pines, MN: American Guidance Service.

Wingate, M. E. (1964). A standard definition of stuttering. Journal of Speech and Hearing Disorders, 29(4), 484-489.

Yairi, E., \& Ambrose, N. (2005). Early childhood stuttering: For clinicians by clinicians. Austin, TX: Pro-Ed.

Zebrowski, P. M. (1995). Stuttering. In J. B. Tomblin, H. L. Morris, \& D. C. Spriestersbach (Eds.), Diagnosis in speech-language pathology (pp. 215-244). San Diego, CA: Singular. 
- 전희정 (HeeCheong Chon) 교신저자

조선대학교 언어치료학과 부교수

광주광역시 동구 필문대로 309

Tel: 062-230-7857

Email: hchon@chosun.ac.kr

관심 분야: 발달성말더듬, 말운동통제, 비유창성

\section{- Torrey M. Loucks}

Associate Professor, Department of Communication Sciences

and Disorders, University of Alberta

Research Director, Institute for Stuttering Treatment and

Research ISTAR, University of Alberta

8205 114St, 2-70 Corbett Hall, Edmonton, Alberta, T6G 2G4,

Canada

Tel: +1-780-492-2242

Email: loucks@ualberta.ca

Fields of interest: stuttering, speech motor control, sensory feed-

back, speech science 


\title{
말운동 연습과 언어적 복잡성이 말더듬 성인의 조음속도에 미치는 영향*
}

\author{
전 희 정 ${ }^{1}$ Torrey M. Loucks ${ }^{2,3}$ \\ 조선대학교 언어치료학과, ${ }^{2}$ Department of Communication Sciences and Disorders, University of Alberta, \\ ${ }^{3}$ Institute for Stuttering Treatment and Research ISTAR, University of Alberta
}

\begin{abstract}
국문초록
본 연구는 조음속도를 사용하여 말더듬 성인과 일반 성인의 말운동 특성과 운동기술 학습 능력을 비교하고, 언어 적 복잡성이 조음속도에 영향을 미치는지 살펴보았다. 연구 참여자는 말더듬 성인 11 명, 일반 성인 11 명이었다. 각 참여자는 길이와 구문적 복잡성이 다른 4 개의 문장(짧고 단순한 문장, 길고 단순한 문장, 길고 복잡한 문장, 길고 구 문적 오류가 있는 문장)을 반복해서 산출하였으며, 문장별로 전체 조음속도 및 문장산출 순서에 따른 조음속도를 측정하였다. 연구 결과, 언어적 복잡성과 상관없이 말더듬 성인은 일반 성인보다 전체 조음속도가 유의하게 느린 것으로 나타났다. 또한 긴 문장들이 짧고 단순한 문장보다 조음속도가 유의하게 느린 것으로 나타났다. 문장산출 순서에 따른 조음속도 비교 결과, 두 집단은 모든 문장에서 중간 4 개 문장과 마지막 3 개 문장의 조음속도가 첫 3 개 문장의 조음속도보다 유의하게 빠른 모습을 보였다. 길고 구문적 오류가 있는 문장은 중간 4 개 문장의 조음속도보 다 마지막 3 개 문장의 조음속도가 유의하게 빨라 지속적인 연습효과를 보인 반면, 다른 세 개의 문장들은 중간 4 개 문장의 조음속도와 마지막 3 개 문장의 조음속도에 차이가 없는 것으로 나타났다. 본 연구를 통하여 말더듬 성인이 일반 성인보다 상대적으로 미숙한 말운동통제 능력을 보이는 것을 알 수 있었으며, 문장의 길이와 구문적 복잡성이 조음속도에 영향을 미치는 요인임을 확인하였다. 또한 말더듬 성인과 일반 성인은 문장을 반복적으로 산출하며 조 음속도가 빨라지는 연습효과를 보였으며, 연습효과가 나타나는 패턴은 두 집단이 비슷하다는 것을 알 수 있었다.
\end{abstract}

핵심어: 말더듬 성인, 조음속도, 연습효과, 말운동통제

\section{참고문헌}

박진, 오선영, 전제표, 강진석 (2015). 배경소음상황에 따른 성인 말더듬화자의 발화 관련 변수 비교. 말소리와 음성과학, 7(1), 27-37.

박진원, 권도하 (2010). 말더듬 성인의 심한 정도에 따른 구어속 도 특성 비교연구. 특수교육저널: 이론과 실천,11(1), 129-146. 안종복, 신명선, 권도하 (2002). 정상 성인 및 아동의 구어속도에 관한 연구. 음성과학, 9(4), 93-103.

이수복, 심현섭 (2015). 초기 말더듬아동의 치료후 말더듬회복 예 측요인에 관한 종단연구: 발화길이를 중심으로. 언어청각장 애연구, 20(2), 189-201.

전희정, 이수복 (2016). 취학 전 말더듬 아동의 말더듬 중증도에 따른 발화 형태별 조음속도 비교. 말소리와 음성과학, 8(3),

\section{9-90.}

전희정, 이수복 (2019). 말더듬 성인의 유창한 발화와 비유창한 발화의 말속도 및 발화 길이 특성. 청능재활, 15(3), 214-222.

\footnotetext{
* 본 연구는 University of Illinois at Urbana-Champaign의 Illinois International Stuttering Research Program과 NeuroSpeech Lab에서 실시되었으며, 제 1 저자의 박사학위 논문을 위해 수집한 자료를 사용하였음. 본 연구는 National Institutes of Health, National Institute on Deafness and Other Communication Disorders의 연구비(\# R01-DC05210, Ehud Yairi, original PI; Nicoline G. Ambrose, second PI; Torrey M. Loucks, Co-PI)와 University of Illinois Research Board의 연구비(Torrey M. Loucks, PI) 지원을 받았음.
} 